\title{
Phytochemical Analysis and Antimicrobial Activity of Smilax ovalifolia Roxb. Ex D. Don
}

\author{
Damaru Prasad Paneru ${ }^{I}$ and Meena Rajbhandari ${ }^{2 *}$ \\ ${ }^{I}$ Central Department of Chemistry, Tribhuvan University, Kathmandu \\ ${ }^{2}$ Research Center for Applied Science and Technology, Tribhuvan University, \\ Kathmandu \\ *Corresponding Author \\ Karmacharyameena@gmail.com
}

\begin{abstract}
Hexane, dichloromethane, ethyl acetate, methanol and 50\% aqueous methanol extracts of S. ovalifolia were screened for the presence of different classes of phytochemicals as well as their antibacterial activity. The phytochemical screening revealed the presence of phenolic, flavonoid and carbohydrate in methanol and $50 \%$ aqueous methanol extracts of $S$. ovalifolia. The antibacterial susceptibility was studied against $E$. coli and $S$. aureus. Among all the tested extracts, ethyl acetate extract showed good antibacterial activity against both bacteria. In the methanol and 50\%, aqueous methanol extracts of S. ovalifolia, total phenolic, total flavonoid and total carbohydrate content were estimated, and free radical scavenging activity was determined. Total phenolic content was measured spectrophotometrically by using FolinCiocalteu reagent, total flavonoid content by using aluminium chloride and total carbohydrate content by using the anthrone method. Gallic acid was used as the standard for the calibration of phenolics, catechin for flavonoids and glucose for carbohydrates. The highest amount of phenolic and flavonoid were found in methanol extract (192.152 $\pm 0.009 \mathrm{mg} \mathrm{GAE} / \mathrm{g}$ extract and $78.188 \pm 2.719 \mathrm{mg} \mathrm{CE} / \mathrm{g}$ extract), respectively. The highest amount of sugar was found in $50 \%$ methanol extract $(190.585 \pm 2.445 \mathrm{mg} \mathrm{GE} / \mathrm{g}$ extract). Methanol extract also showed good antioxidant activity $\left(\mathrm{IC}_{50}\right.$ value $\left.49.989 \mu \mathrm{g} / \mathrm{ml}\right)$ than $50 \%$ aqueous methanol extract $\left(\mathrm{IC}_{50} 72.021 \mu \mathrm{g} / \mathrm{ml}\right)$. The GC-MS analysis of hexane extract of $S$. ovalifolia allowed the identification of 16 phyto-constituents based on retention time and the fragmentation pattern in the mass spectrum.
\end{abstract}

\section{Keyword}

Antimicrobial, antioxidant, GC-MS, total flavonoid, total phenolic, total sugar

\section{Introduction}

Smilax ovali folia Roxb. ex D. Don locally known as KUKURDIANO belongs to Smilacaceae family is a twining shrub armed with some prickles. Traditionally, leaves are eaten as vegetables, and fleshy young shoots are eaten raw, stems are used as toothbrush to cure toothache, roots are used in skin diseases, muscular sprain, arthritis, stomach pain, rheumatic disease, blood dysentery and urinary complaints, the juice, decoction or paste of the plant is widely used to treat diverse ailments (Shah 2015). Root juice is used to cure venereal disease, rheumatism and wounds (Malla, et al., 2014).
The genus Smilax is known to contain 300-350 species and distributed worldwide in temperate, tropical and sub-tropical zones. Many species of the genus Smilax is well investigated phytochemically and pharmacologically. However, a survey of the recent literature showed rather scarce data on S. ovalifolia. Total phenolic, flavonoid and DPPH antioxidant activity of alcoholic extract of the leaf (Shah 2015b) and phytochemical, toxicity and hepato-protectivity of the root has been reported (Noor et al., 2014).

Antimicrobial drug resistance and hospitalacquired nosocomial infection is an ever-growing problem in developing country like Nepal. It 
has important implications in the morbidity, mortality and health care cost in hospitals as well as in the community (Struelens1998). Therefore, preventive measures must be adopted, and alternative therapeutic means must be developed to avoid such opportunistic infections. Otherwise, this will threaten the whole society and the community. Hence the search for more safe and effective antimicrobial compounds is most important, and it is interesting to test the plant extracts with different etiological agents.

Phytomedicines have been used for thousands of years in traditional systems of health care to treat a wide range of ailments. The World Health Organization has emphasized the use of traditional medicine in developing affordable drugs (Patwardhan 2005; Patwardhan \& Vaidyab 2010). In most cases, plant extracts contain complex mixtures of secondary metabolites, and their combined action can yield an enhanced synergetic effect (Cowan 1994). Among the secondary metabolites, dietary phenolics have received tremendous attention among nutritionists, food scientists and consumers due to their roles in human health. Recent research confirmed the role of polyphenols in the prevention of free radicalinduced oxidative damage which is responsible for the pathogenesis of many chronic and degenerative diseases such as cancers, cardiovascular diseases, diabetes, ageing and neurodegenerative diseases (Ames et al., 1993 Khan \& Wilson 1995).

The search for materials containing antimicrobial and antioxidants activity continues to attract the attention of researchers in the food and pharmaceutical industries. The formulation of nutraceuticals/functional food requires information about biological properties, toxicity assay, as well as the chemical composition of the plants. The search for plants with broad pharmacological activities, low toxicity and nutrient-rich healthy carbohydrates is gaining importance in recent years. It was suggested that there is an association between obesity and cancer. The intakes of natural carbohydrate reduce the risk of obesity, diabetes and cardiovascular diseases. This may ultimately reduce cancer risk (Mann et. al., 2007). Therefore, the assessment of such properties remains an interesting and useful task, mainly to find new promising sources of natural antioxidants for functional foods and nutraceuticals. Hence the main aim of the present study is focused on the identification of phytochemicals present in different extracts, determination of total phenolic, total flavonoid, total sugar content, antioxidant, antibacterial activity and chemical composition of hexane extract of S.ovalifolia leaves by GC-MS. This is the first attempt to investigate the constituents of hexane extract to explore its possible medicinal value.

\section{Plant Materials}

The plant material was collected from community forest of Kailai district of western Nepal in February 2016 and authenticated by comparing with the voucher specimens deposited at Central Department of Botany Tribhuvan University, Kathmandu, Nepal. The voucher specimen (DPP16) was deposited at RECAST.

\section{Solvents and chemicals}

DPPH and authentic $( \pm)$-catechin were purchased from Sigma Chemical Company, USA. Gallic acid was purchased from Merck, Darmstadt, Germany. Aluminium chloride reagent (SD fine-chemicals), Folin-Ciocalteu reagent (SD fine-chemicals) and anthrone (Thomas baker) were obtained from the local vendor. All other chemicals and solvents were of analytical grade and purchased from local vendors.

\section{Extraction}

The dried and powdered leaves of $S$. ovalifolia $(100 \mathrm{~g})$ were extracted successively with hexane $(250 \mathrm{~mL}, 6$ times, $18 \mathrm{~h})$, dichloromethane (300 $\mathrm{mL}, 6$ times, $18 \mathrm{~h})$, ethyl acetate $(200 \mathrm{~mL}, 4$ times, $18 \mathrm{~h})$ and methanol $(200 \mathrm{~mL}, 5$ times, $18 \mathrm{~h})$ by cold percolation. The residue after extraction with methanol was refluxed with $50 \%$ aqueous methanol $(400 \mathrm{~mL}, 4 \mathrm{~h})$. The extracts were filtered, and the solvent was evaporated under reduced pressure in a Rota vapor to get several crude extracts. The dried extracts were stored at $-20{ }^{\circ} \mathrm{C}$ for further use.

\section{Phytochemical screening}

The freshly prepared crude extracts were subjected to chemical tests to identify various classes of chemical constituents present in the extracts using standard procedures (Harborne 1973). 


\section{Antibacterial assay}

One Gram-positive bacteria, Staphylococcus aureus (ATCC 25923) and one Gram-negative bacteria, Escherichia coli (ATCC 25922) were used to determine the antibacterial activity of the extracts.Agar well diffusion method was used to determine the antimicrobial activity (Bauer et al., 1966). The sterile Mueller-Hinton agar plates were inoculated with respective bacteria. The wells of $6 \mathrm{~mm}$ diameter were made in the inoculated agar plates with the help of a sterile cork borer. Then, each $100 \mu \mathrm{l}$ of the plant extracts prepared in DMSO (50 \& $100 \mathrm{mg} / \mathrm{mL})$ were loaded into the respective wells. Negative control experiments were performed by using an equivalent volume of DMSO, and positive control experiments were performed by use of the standard antibiotic, amoxicillin disc $(10 \mu \mathrm{g} / \mathrm{well})$. The plates were then left for half an hour so that the extracts diffuse into the media. Then the plates were incubated overnight at $37 \mathrm{C}$. At the end of the incubation period, the clear zones of inhibition around the wells were measured.

\section{Determination of total phenolic content in different extracts}

The total phenolic content in plant extracts was determined by using the FolinCiocalteucolourimetric method based on oxidation-reduction reaction (Waterhouse 2002). Various concentrations of gallic acid solutions in methanol $(10,25,50,75$ and $100 \mu \mathrm{g} / \mathrm{mL})$ were prepared. In a $20 \mathrm{~mL}$ test tube, $1 \mathrm{~mL}$ gallic acid of each concentration was added and to that 5 $\mathrm{mL}$ Folin-Ciocalteu reagent (10\%) and $4 \mathrm{~mL} \mathrm{7 \%}$ $\mathrm{Na}_{2} \mathrm{CO}_{3}$ was added to get a total volume of 10 $\mathrm{mL}$. The blue coloured mixture was shaken well and incubated for 30 minutes at $40 \mathrm{C}$ in a water bath. Then, the absorbance was measured at 760 $\mathrm{nm}$ against a blank containing all reagents except gallic acid. All the experiments were carried out in triplicate. The average absorbance values obtained at different concentrations of gallic acid were used to plot the calibration curve.

Various concentrations of the extracts $(200,100$, 50 and $25 \mu \mathrm{g} / \mathrm{mL}$ ) were prepared. Following the procedure described for standard, absorbance for each concentration of the extract was recorded. Total phenolic content of the extracts was expressed as mg gallic acid equivalents (GAE) per gram dry extract $(\mathrm{mg} / \mathrm{g})$.

\section{Determination of total flavonoid content}

The total flavonoid content was determined by aluminium chloride colourimetric assay(Zhishen et al., 1999). Various concentrations of standard catechin $(10,25,50,75$ and $100 \mu \mathrm{g} / \mathrm{mL})$ were prepared. An aliquot of $1 \mathrm{~mL}$ catechin of each concentration in methanol was added to a 10 $\mathrm{mL}$ test tube containing $4 \mathrm{~mL}$ double distilled

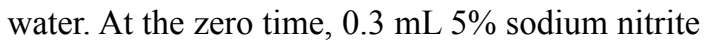
was added, after $5 \mathrm{~min}, 0.3 \mathrm{~mL}$ of $10 \% \mathrm{AlCl}_{3}$ was added, and at $6 \mathrm{~min}, 2 \mathrm{~mL}$ of $1 \mathrm{M}$ sodium hydroxide was added to the mixture. Immediately, the total volume of the mixture was made up to $10 \mathrm{~mL}$ by the addition of $2.4 \mathrm{~mL}$ double distilled water and mixed thoroughly. The absorbance of the pink coloured mixture was determined at 510 $\mathrm{nm}$ against a blank containing all reagents except catechin. The average absorbance values obtained at different concentrations of catechin were used to plot the calibration curve.

Various concentrations of the extracts (200, 100,50 and $25 \mu \mathrm{g} / \mathrm{mL}$ ) were prepared. Following the procedure described for standard, absorbance for each concentration of the extract was recorded. Total flavonoid content of the extracts was expressed as $\mathrm{mg}$ catechin equivalents (CE) per gram of dry extract $(\mathrm{mg} / \mathrm{g})$.

\section{Determination of total sugar content}

The total sugar content in plant extracts was estimated by using anthrone reagent based colourimetric method (Hedge \& Hofreiter 1962). Various concentrations of D-glucose $(10,25,50$ and $75 \mu \mathrm{g} / \mathrm{mL}$ ) were prepared. An aliquot of $2 \mathrm{~mL}$ glucose of each concentration and $8 \mathrm{~mL}$ of freshly prepared anthrone reagent $(200 \mathrm{mg}$ of anthrone in $100 \mathrm{~mL}$ of ice-cold $95 \% \mathrm{H}_{2} \mathrm{SO}_{4}$ ) was mixed in $15 \mathrm{~mL}$ test tube. The mixture was shaken well and heated for 8 minutes at boiling water bath. Then cooled rapidly and the absorbance of green coloured solution was measured at $630 \mathrm{~nm}$ against a blank containing all reagents except sugar. All the experiments were carried out in triplicate. The absorbance values obtained are used separately to plot calibration curve.

An amount of $100 \mathrm{mg}$ each extract was dissolved 
in methanol, $5 \mathrm{~mL}$ of $2.5 \mathrm{~N} \mathrm{HCl}$ was added and subjected to hydrolysis by keeping it in a boiling water bath for $3 \mathrm{hrs}$ then cooled and neutralized with solid sodium carbonate and make up the volume to $100 \mathrm{~mL}(1 \mathrm{mg} / \mathrm{mL})$. Serial dilutions were carried out to get the concentration of 100,200 , 400 and $600 \mu \mathrm{g} / \mathrm{mL}$. To these diluted solutions, anthrone reagent was added and heated for 8 minutes as in the case of glucose and absorbance was measured at $630 \mathrm{~nm}$ against a blank.

\section{Calculation}

The total phenolic, flavonoid, and sugar content were calculated in all the extracts separately using the formula, below.

$$
\mathrm{C}=\frac{\mathrm{cV}}{\mathrm{m}} \ldots \ldots \ldots \ldots \ldots \ldots
$$

Where, $\mathrm{C}=$ Total content of flavonoid/phenol/ sugar compounds in $\mathrm{mg} / \mathrm{g}, \mathrm{c}=$ Concentration of gallic acid/ $( \pm)$-catechin/D-glucose established from the calibration curve in $\mathrm{mg} / \mathrm{mL}, \mathrm{V}=$ Volume of extract in $\mathrm{mL}, \mathrm{m}=$ Weight of plant extract.

\section{Statistical analysis}

Data were recorded as a mean \pm standard deviation of three determinations of absorbance for each concentration, from which the linear correlation coefficient $\left(\mathrm{R}^{2}\right)$ value was calculated using MS Office Excel 2007. The linear regression equation for a straight line is, $\mathrm{y}=\mathrm{mx}+\mathrm{c}$ where, $\mathrm{y}=$ absorbance of extract, $\mathrm{m}=$ slope of the calibration curve, $\mathrm{x}=$ concentration of extract, $\mathrm{c}=$ intercept. Using this regression equation, concentrations of extracts were calculated. From the calculated values of concentration of each extract, the total phenolics, flavonoid and sugar content were calculated.

\section{Determination of antioxidant activities using 2,2-Diphenyl-1-picrylhydrazyl (DPPH) radical scavenging assay}

Antioxidant activity of the selected extracts was assessed using DPPH free radical (Brand-William et al., 1995). DPPH solution (0.1 mM) was prepared by dissolving $3.9 \mathrm{mg}$ of DPPH in 100 $\mathrm{mL}$ methanol and stirred overnight at $4 \mathrm{C}$. Thus, made purple coloured DPPH free radical solution was stored at $-20 \mathrm{C}$ for further use.
Three different concentrations $(5,10,15$ and 20 $\mu \mathrm{g} / \mathrm{mL}$ ) of methanolic solutions of each extract were prepared by the serial dilution of the stock solution of the respective extract. To each 0.5 $\mathrm{mL}$ extract solution, $2.5 \mathrm{~mL} 0.1 \mathrm{mM}$ methanolic DPPH solution was added. A control was prepared by mixing $0.5 \mathrm{~mL}$ distilled water and $2.5 \mathrm{~mL} 0.1$ $\mathrm{mM}$ methanolic DPPH solution. These samples were shaken well and kept in the dark for 30 min at room temperature. The absorbance was measured at $517 \mathrm{~nm}$ against the blank solution consisting of $2.5 \mathrm{~mL} \mathrm{MeOH}$ and $0.5 \mathrm{~mL}$ distilled water. The radical scavenging activity was expressed as the radical scavenging percentage using the equation (1) where; $A_{S}=$ absorbance of the sample solution, $A_{b}=$ absorbance of blank and $A_{C}=$ absorbance of control.

$$
\% \text { scavenging }=\left[\frac{(A s-A b)}{A c}\right] \times 100
$$

The $\mathrm{IC}_{50}$ value is the concentration of sample required to scavenge $50 \%$ of DPPH free radical and was calculated from the plotted graph of radical scavenging activity against the concentration of extracts.

\section{GC-MS analysis}

Analytical GC-MS of hexane extract was carried out on JEOLAccuTOF GCX Time of Flight Mass-spectrometer fitted with Agilent 7693A type GC injector and an HP5 capillary column (29.2 $\mathrm{m} \times 0.25 \mathrm{~mm}$ i.d., film thickness $0.25 \mu \mathrm{m}$ ). The initial oven temperature was $80 \mathrm{C}$ with hold time of 1 minute. The temperature was gradually increased to $320 \mathrm{C}$ at a rate of $15 \mathrm{C} /$ minute and kept at the final temperature for 5 minutes. The maximum oven temperature was maintained at $325 \mathrm{C}$ with an equilibrium time of 1 minute. The ion chamber temperature was $250 \mathrm{C}$ while the $\mathrm{GC}$ interface temperature and inlet temperature was kept at 300C. Diluted sample $(0.5 \mu \mathrm{L})$ was injected in the splitless mode. Helium was used as a carrier gas with a flow rate of $1.2 \mathrm{~mL} / \mathrm{min}$. MS was operated in electron impact mode with ionization energy of $70 \mathrm{eV}$. Full scan mass spectra were acquired from 25-600 amu. The total run time was 22 minutes. The detected compounds were identified by processing the raw GC-MS 
data with msAxel software (Version 1.1.6.17127 Copyright 2014-2015 JEOL Ltd.) and comparing with NIST mass spectral library (Mass spectral Program for the National Institute of Standards and Technology/Environment Protection Agency/ National Institute of Health Mass Spectral Library, Version 2.2).

\section{Results and Discussion}

\section{Phytochemical screening}

The plant material was successively extracted with hexane, dichloromethane, ethyl acetate and methanol. The residue was refluxed with $50 \%$ aqueous methanol to get the respective extracts. The highest amount of extract was obtained with $50 \%$ methanol, and the lowest amount was obtained with dichloromethane. The results of the yield of extracts and phytochemical screening of extracts $S$. ovalifolia are shown in Table 1.

\section{Antibacterial susceptibility assay}

The hexane, dichloromethane, ethyl acetate, methanol and 50\% aqueous methanol extracts were screened for antimicrobial activity against one Gram-positive bacteria $S$. aureus and one Gram-negative bacteria $E$. coli by agar well diffusion method. The results are shown in Table 2. The results of antibacterial assay revealed that except the hexane extract all the other extracts showed moderate activity against both bacteria. The ethyl acetate extract showed the highest activity against $E$. coli.

\section{Estimation of total phenolic content (TPC)}

A simple and reproducible Folin-Ciocalteu (FC) method was applied for the determination of total phenolic content using gallic acid as a standard although there is possible interference from other readily oxidizable compounds present in the plant extracts. The absorbance values obtained at different concentrations of gallic acid was used for the construction of a calibration curve. FC method is based on the transfer of electrons in alkaline medium from phenolic compounds to phosphomolybdic/ phosphotungstic acid complexes to form blue coloured complexes, $\left(\mathrm{PMoW}_{11} \mathrm{O}_{40}\right)^{-4}$, that is determined spectrophotometrically at $760 \mathrm{~nm}$. The total phenolic content in different extracts was calculated from the calibration curve using regression equation $\mathrm{Y}=0.013 \mathrm{x}, \mathrm{R}^{2}=0.999$ followed by the formula $\mathrm{C}=\mathrm{cV} / \mathrm{m}$ and expressed as $\mathrm{mg}$ gallic acid equivalent (GAE) per $\mathrm{g}$ of extract in dry weight $(\mathrm{mg} / \mathrm{g})$. The results indicated that the total phenolic content in methanol extracts (192.152 $\pm 0.009 \mathrm{mg}$ GAE/g extract) was found to be slightly higher than in $50 \%$ aqueous methanol extract (184.804 $\pm 0.017 \mathrm{mg}$ GAE/g extract). It was reported that (Shah 2015b) the total phenol content in methanol extract was $(8.34 \pm 0.02$ $\mathrm{mg} \mathrm{GAE} / \mathrm{g})$ and in ethanol extract was $(10.87 \pm$ $0.043 \mathrm{mg} \mathrm{GAE} / \mathrm{g})$. In comparison to the literature data, the total phenolic content in our sample is relatively high. The results are shown in Table 2 .

Estimation of total flavonoid content (TFC)

Table 1. Yield and phytochemical screening of different extracts of $S$. ovalifolia leaf

\begin{tabular}{lccccc}
\hline \multicolumn{1}{c}{ Extract } & Hexane & $\mathrm{CH}_{2} \mathrm{Cl}_{2}$ & EtOAc & $\mathrm{MeOH}$ & $\mathbf{5 0 \%} \mathrm{MeOH}$ \\
Yield & $5.60 \mathrm{~g}$ & $\mathbf{4 . 4 0} \mathrm{g}$ & $\mathbf{5 . 2 3} \mathrm{g}$ & $\mathbf{1 1 . 5 0 \mathrm { g }}$ & $\mathbf{1 3 . 8 0 \mathrm { g }}$ \\
\hline Volatile oil & - & - & & - & - \\
Phenolics & - & - & - & + & + \\
Flavonoids & - & - & - & + & + \\
Alkaloids & - & - & - & - & - \\
Terpenoids & - & - & - & + & + \\
Glycosides & - & - & - & + & + \\
Saponines & - & - & - & + & - \\
Tannins & - & - & - & + & + \\
Reducing sugars & - & - & + & + \\
Quinones & - & & & & + \\
\hline
\end{tabular}

$(+)$ indicates present and (-) indicates absent 
The total flavonoid content in different extracts was estimated by aluminium chloride colourimetric assay using $( \pm)$-catechin as a standard. The absorbance values obtained to varying concentrations of catechin was used for the construction of a calibration curve. The principle involved in aluminium chloride $\left(\mathrm{AlCl}_{3}\right)$ colourimetric method is that $\mathrm{AlCl}_{3}$ forms acidstable complexes with either keto groups and/ or group of flavones and flavonols. Besides, it also forms acid-labile complexes with the ortho-dihydroxyl groups of the flavonoids which give pink colour in an alkaline medium whose absorbance was measured spectrophotometrically. The total flavonoid content in different extracts was calculated from the calibration curve using regression equation $\mathrm{Y}=0.004 \mathrm{x}, \mathrm{R}^{2}=0.991$ followed by the formula $\mathrm{C}=\mathrm{cV} / \mathrm{m}$ and expressed as $\mathrm{mg}( \pm)$-catechin equivalent (CE) per $\mathrm{g}$ of extract in dry weight $(\mathrm{mg} / \mathrm{g})$. The result of this investigation indicated that the total flavonoid content in methanol extract $(78.188 \pm 2.719 \mathrm{GAE} / \mathrm{g}$ extract) was found to be relatively higher when compared with $50 \%$ aqueous methanol extract $(61.875 \pm 2.839 \mathrm{GAE} / \mathrm{g}$ extract). It was reported that (Shah, 2015b) the total flavonoid content in methanol extract was $(5.16 \pm 0.033 \mathrm{mg} \mathrm{QE} / \mathrm{g})$ and in ethanol extract was $(7.65 \pm 0.011 \mathrm{mg} \mathrm{GAE} / \mathrm{g})$. In comparison to the literature, the total flavonoid content in our sample is relatively high. The results are shown in Table 2 .

The ratios of total flavonoid to total phenolic content were found to be different in methanol and $50 \%$ aqueous methanol extracts. In the case of methanol extract, slightly higher ratio (0.406) was observed, which indicated that $40.6 \%$ of total phenolics are flavonoids. Similarly, in the case of $50 \%$ methanol extract, the ratio $(0.334)$ was observed, which indicated that $33.4 \%$ of total phenolics are flavonoids. The results are shown in Table 2.

\section{Estimation of total sugar content}

Anthrone reagent based colourimetric assay using D-glucose as a standard was used to determine the total sugar content in plant extracts. Plant extracts containing sugars were first hydrolyzed into simple sugars using dilute hydrochloric acid. In hot acidic medium glucose is dehydrated to hydroxymethylfurfural that with anthronale, an

Table 2. Antimicrobial activity, total phenolic, flavonoid, sugar and antioxidant activity of different extracts of S.ovalifolia

\begin{tabular}{|c|c|c|c|c|c|c|c|c|c|}
\hline \multirow[b]{2}{*}{$\begin{array}{l}\text { Plant } \\
\text { extracts }\end{array}$} & \multirow[b]{2}{*}{ Bacteria } & \multicolumn{3}{|c|}{ Inhibition zone (mm) } & \multirow[b]{2}{*}{$\begin{array}{c}\text { ТРC } \\
\mathrm{mg} \mathrm{GAE} / \mathrm{g}\end{array}$} & \multirow[b]{2}{*}{$\begin{array}{c}\mathrm{TFC} \\
\mathrm{mg} \mathrm{CE} / \mathrm{g}\end{array}$} & \multirow{2}{*}{$\begin{array}{l}\text { Ratio } \\
\text { TF/TP }\end{array}$} & \multirow[b]{2}{*}{$\begin{array}{c}\mathrm{TSC} \\
\mathrm{mg} \mathrm{GE} / \mathrm{g}\end{array}$} & \multirow{2}{*}{$\begin{array}{c}\mathrm{DPPH} \\
\mathrm{IC}_{50} \\
(\mu \mathrm{g} / \\
\mathrm{ml})\end{array}$} \\
\hline & & $\begin{array}{l}5 \mathrm{mg} / \\
\text { well }\end{array}$ & $\begin{array}{c}10 \\
\mathrm{mg} / \\
\text { well }\end{array}$ & Control & & & & & \\
\hline \multirow{2}{*}{ Hexane } & E. coli & - & - & - & \multirow[b]{2}{*}{ - } & \multirow[b]{2}{*}{-} & \multirow[t]{2}{*}{-} & \multirow[b]{2}{*}{ - } & \multirow[b]{2}{*}{ - } \\
\hline & S. aureus & - & - & - & & & & & \\
\hline \multirow{2}{*}{ DCM } & E. coli & 15 & 16 & - & \multirow{2}{*}{-} & \multirow{2}{*}{-} & \multirow[t]{2}{*}{-} & \multirow{2}{*}{-} & \multirow{2}{*}{-} \\
\hline & S. aureus & 14 & 15 & - & & & & & \\
\hline \multirow{2}{*}{ EtOAc } & E. coli & 17 & 19 & - & \multirow{2}{*}{-} & \multirow{2}{*}{ - } & \multirow{2}{*}{-} & \multirow{2}{*}{-} & \multirow{2}{*}{ - } \\
\hline & S. aureus & 16 & 17 & - & & & & & \\
\hline \multirow{2}{*}{$\mathrm{MeOH}$} & E. coli & 15 & 16 & - & \multirow{2}{*}{$192.15 \pm 0.01$} & \multirow{2}{*}{$78.18 \pm 2.72$} & \multirow{2}{*}{0.406} & \multirow{2}{*}{$174.49 \pm 3.16$} & \multirow{2}{*}{49.989} \\
\hline & S. aureus & 14 & 15 & - & & & & & \\
\hline \multirow{2}{*}{$\begin{array}{l}50 \% \\
\mathrm{MeOH}\end{array}$} & E. coli & 16 & 17 & - & \multirow{2}{*}{$184.80 \pm 0.02$} & \multirow{2}{*}{$61.87 \pm 2.84$} & \multirow{2}{*}{0.334} & \multirow{2}{*}{$190.58 \pm 2.45$} & 72021 \\
\hline & S. aureus & 15 & 16 & - & & & & & 72.021 \\
\hline & E. coli & & & 22 & & & - & & \\
\hline $\begin{array}{l}\text { Amoxi- } \\
\text { cillin }\end{array}$ & S. aureus & & & 36 & - & - & & - & - \\
\hline & S. aureus & & & 9 & & & & & \\
\hline
\end{tabular}

Note: Inhibition zone was measured including well and disc 
enol form of anthrone forms a green coloured product with an absorption maximum at $630 \mathrm{~nm}$ which was measured against a blank consisting of anthrone solution and distilled water. The absorbance values obtained at different concentrations of glucose was used for the construction of the calibration curve. The total sugar content in different extracts was calculated from the calibration curve using regression equation $\mathrm{Y}=0.013 \mathrm{x}, \mathrm{R}^{2}=0.994$ followed by the formula $\mathrm{C}=\mathrm{cV} / \mathrm{m}$ and expressed as $\mathrm{mg}$ glucose equivalents (GE) per $\mathrm{g}$ of extract in dry weight $(\mathrm{mg} / \mathrm{g})$. The highest amount of sugar was found in $50 \%$ aqueous methanol extract $(190.585 \pm 2.445$ $\mathrm{GE} / \mathrm{g}$ ) while a slightly lower amount of sugar was found in methanol extract $(174.491 \pm 3.160 \mathrm{GE} / \mathrm{g})$. The results are shown in Table 2.

\section{Determination of antioxidant activity using DPPH free radical}

The DPPH assay was carried out for methanol and $50 \%$ aqueous methanol extracts of $S$. ovalifolia. The absorbance values were measured at 517 $\mathrm{nm}$ for different concentrations of extracts and the control. These values were used to calculate the percentage inhibitions of DPPH radicals against the samples. The $\mathrm{IC}_{50}$ values of various extracts were calculated from the percentage inhibitions at various concentrations are given in Table 2. The results showed that the $\mathrm{IC}_{50}$ value of methanol extract of $S$. ovalifolia was found to be lower $(49.989 \mu \mathrm{g} / \mathrm{mL})$ than the $\mathrm{IC}_{50}$ value of $50 \%$ aqueous methanol extract $(72.021 \mu \mathrm{g} / \mathrm{mL}$ ). However, the reported date for the methanol extract was $26.12 \mu \mathrm{g} / \mathrm{mL}$, and ethanol extract was $17.43 \mu \mathrm{g} / \mathrm{mL}$ (Shah 2015b). This variation may be due to the variation in the active constituents present in the plant as well as the extraction method. The lower the $\mathrm{IC}_{50}$ value, the higher the antioxidant activity.

\section{The GC-MS analysis of hexane extract of $S$. ovalifolia}

The chemical composition of hexane extract of $S$. ovalifolia was determined by GC-MS technique. The GC-MS analysis of hexane extract of $S$. ovalifolia allowed the identification of 16 Phytoconstituents based on retention time and the fragmentation pattern in the mass spectrum. They were categorized into three acyclic hydrocarbons, one alcohol, one vitamin E, one steroidal hydrocarbon, one phthalate, five esters compounds, one aldehyde, two sterols, and one lactone. The phyto constituents are shown in Table 3.

\section{Table 3. Phytoconstituents of hexane extract of $S$. ovalifolia leaf}

\begin{tabular}{llc}
\hline S. N & \multicolumn{1}{c}{ Compound Name } & RT \\
\hline 1 & Neophytadiene & 9.86 \\
2 & 14-methyl- pentadecanoate & 10.44 \\
3 & Methyl 9-cis,11-trans-octadecadienoate & 11.58 \\
4 & Ethyl 9,12,15-octadecatrienoate & 11.59 \\
5 & Phytol & 11.66 \\
6 & (Z,Z, Z)-9,12,15-octadecatrienoate & 11.98 \\
7 & 4,8,12,16-tetramethylheptadecan-4-olide & 13.07 \\
8 & (Z)-13-docosenoate & 13.84 \\
9 & Bis (2-Ethylhexyl) phthalate & 14.10 \\
10 & Nonacosane & 15.74 \\
11 & Cholest-4-en-26-oic acid, 3-oxo-, methyl ester & 16.19 \\
12 & Tetratriacontane & 16.63 \\
13 & Stigmasta-3,5-diene & 16.79 \\
14 & Vitamin E & 16.89 \\
15 & B- Sitosterol & 17.81 \\
16 & Tricosanal & 18.23 \\
\hline
\end{tabular}




\section{Conclusion}

There is a growing interest in natural antioxidants in food because they play an essential role in the physiological system to prevent oxidative damage to cellular components. Medicinal herbs are one of the most important targets to search for natural antioxidants. However, in Nepalese culture, many medicinal plants have not received much attention as sources of natural antioxidants. The present research highlighted the antibacterial activity, total phenolic, total flavonoid, total sugar content, the antioxidant property of different extracts and chemical composition of hexane extract of the plant $S$. ovalifolia. It can be used as a value-added processed product or nutraceutical or as an additive to prolong the life of food rich in polyunsaturated fats. Thus, the utilization of underexploited resources and better evaluation of ethnic and traditional knowledge can offer many benefits.

\section{Acknowledgements}

The authors are grateful to Prof. U. Lindequist, the University of Greifswald for providing authentic gallic acid and catechin, Dr Carsten Gruendemann, University of Freiburg and Dr Guido Jurgenliemk, University of Regensburg, Germany for providing GC-MS spectra and University Grants Commission, Bhaktapur for the research grant.

\section{References}

Ames, B. N., M. K. Shigenaga and T. M. Hagen. 1993. Oxidants, antioxidants, and the degenerative diseases of ageing. Proceeding of National Academy of Science U.S.A. 90: 7915-7922

Bauer, A. W., Kirby, M. K., Sherris, J. C., Turck, M., 1996. Antibiotic susceptibility testing by standard single disc diffusion method. American Journal of Clinical Pathology. 45, 493- 496.

B. Malla, D. P. Gauchan and R. B. Chhetri, Journal of Medicinal Plants Research 2014, 8(2), 95-108

Brands, W., Cuveiler, M. E., Berset, C. 1995. Use of a free radical method to evaluate antioxidant activity. Food Science and Technology. 28, 25-30.

Cowan, M. M., 1999. Plant products as antimicrobial agents. Clinical Microbiology Reviews 12: 564582

Harborne, J. B., 1973. Phytochemical Methods,
Chapman and Hall, Ltd., London, pp. 49-188.

Hedge, J. E. and Hofreiter, B. T. 1962. In: Carbohydrate Chemistry. Whistler R. L., BeMiller J. N., Academic Press, New York, PP. 420.

Khan, A.U. and T. Wilson. 1995. Reactive oxygen species as cellular messengers. Chemistry and Biology 2: 437-445

Mann, J., Cummings, J. H., Englyst, H. N., Key, T., Liu, S., Riccardi, G., Summerbell, C., Uauy, R., Dam, R. M., Venn, B., Vorster, H. H., Wiseman, M. 2007. FAO/WHO Scientific Update on carbohydrates in human nutrition: conclusions. European Journal of Clinical Nutrition. 61 (1), S132-S137.

Noor, S. D., Krishnasamy, K., Behbehani, R. S., 2014. In-vitro studies to explore the pharmacognostic, physicochemical, phytochemical, toxicity and hepatoprotective of Smilax ovalifolia root. International Journal of Phytopharmacology 5: 210-217

Patwardhan, B., 2005. Traditional Medicine: Modern approach for affordable global health. In: Commission on Intellectual Property Rights IaPHC, WHO, Geneva

Patwardhan, B. \&Vaidyab, A.D.B., 2010. Natural products drug discovery research in India: Status and appraisal. Indian Journal of Experimental Biology 48: 220-227

Shah, R. K. 2015a. A Review on Ethnobotanical uses of Smilax ovalifolia. International Journal of Herbal Medicine 3:16-19

Shah, R. K. 2015b. Antioxidant activity and estimation of total phenols and flavonoids in extracts of Smilax ovalifolia leaves. International Journal of Pure and Applied Bioscience 3: 174-177

Struelens, M. J., 1998. The epidemiology of antimicrobial resistance in hospital-acquired infections: problems and possible solutions. British Medical Journal 317: 652-654

Waterhouse, A., 2002. Determination of total phenolics. In: Current protocols in food analytical chemistry (Ed Wrolstad, R. E). John Wiley and Sons, New York, Units I1.1.1-I1.1.8.

Zhishen, J., Mengcheng, T., Jianming, W., 1999. The determination of flavonoid contents in mulberry and their scavenging effects on superoxide radicals. Food Chemistry 64: 555-559. 